\title{
Model-Based Quality Assessment of Internet of Things Software Applications: A Systematic Mapping Study
}

\author{
https://doi.org/10.3991/ijim.v14i09.13431 \\ Teeba Ismail Kh. $\left({ }^{凶}\right)$ \\ Lebanese French University (LFU)/Salahaddin University, Erbil, Iraq \\ teeba ismailelfu.edu.krd \\ teeba.ismailesu.edu.krd \\ Ibrahim I. Hamarash \\ University of Kurdistan-Hewler, Salahaddin University-Erbil, Kurdistan Region, Iraq
}

\begin{abstract}
The Internet of things (IoT) is growing at a fast pace owing to its vast applications in varied fields such as medicine, society, economy, and even the military. This growth cannot continue without establishing high quality. Over the past decade, interest in research for the quality assurance of IoT has gradually grown. However, the discipline is still evolving, and further research is required to investigate the various quality-related aspects. Although assessing the entire system is impractical, to assure the quality of IoT applications, various assessment levels are required. A well-known and established approach to mitigate this difficulty is to model the entire system or a few parts of it for the sake of assessment, which is known as model-based testing. To determine what has been achieved thus far and what is lacking in this direction, this paper presents an extensive study on the use of the model-based approach to assure the quality of IoT applications. The study systematically reviews papers published from 2009 (early publications on IoT) to 2019 that reported the explicit use of models to assess the quality aspects of IoT applications. As a result of an extensive search process, the paper presents the results of scanning and reviewing 390 published papers. Thus far, out of these, 54 studies used the model-based approach to assess at least one quality aspect of an IoT application. In addition to the several relevant research questions that have been addressed in this study, this paper also presents several new insights and approaches for future research.
\end{abstract}

Keywords-Internet of Things, IoT, quality assurance, model-based testing, ISO/IEC 25000 quality model

\section{Introduction}

The Internet of things (IoT) is a grid of devices, vehicles, home appliances, or other items embedded with electronics, software, and sensors that enable these objects to connect and exchange data [1]. The number of applications that implement the concepts of IoT is increasing phenomenally. It is expected that the global market value of IoT will reach \$7.1 Billion 2020 [2]. Owing to this rate of expansion, ensuring the quality 
of IoT applications before releasing them into the market is a must. Quality assurance (QA) is a systematic means to check whether a product or service meets the specified requirements and standards stipulated to achieve the desired level of satisfaction for stakeholders. Generally, stakeholders require an application to demonstrate several quality characteristics, such as performance, efficiency, security, or maintainability. These requirements are represented in the quality model. The quality model of software applications has been illustrated extensively in a series of standards within the ISO/IEC 25000, which is known as "Software Quality Requirements and Evaluation" (SQUARE) [3]. The ISO/IEC 25000 quality model covers eight characteristics with 31 sub-characteristics for ensuring software product quality. Figure 1 presents an overview of these characteristics.

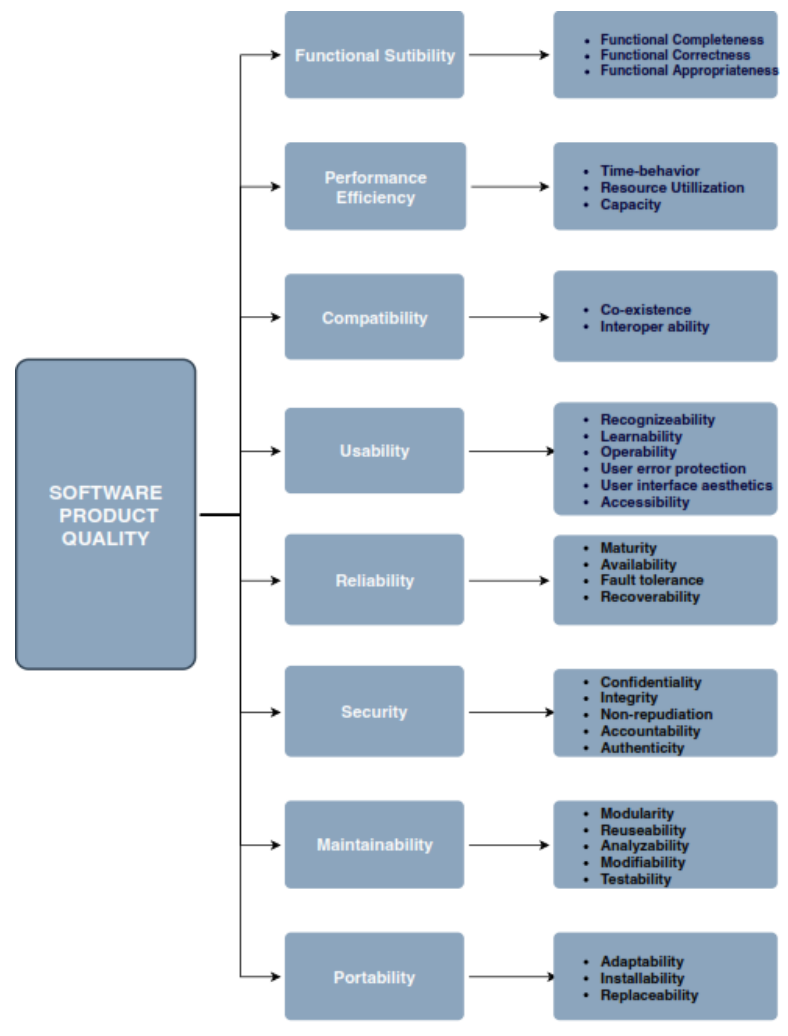

Fig. 1. Standard ISO/IEC 25000

Although there are several analogies between conventional software and IoT software applications, multiple challenges may arise when the well-established methods of software testing and QA are applied to the IoT domain. For example, the distributed nature of the IoT system and unavailability of an implemented established system as a test bed is challenging. Motivated by the huge success of model-based testing (MBT) of conventional software applications, several studies have followed this approach to 
overcome the difficulties encountered in IoT software application testing. Currently, MBT is one of the promising approaches in this direction. Originally, MBT was a testing approach in which both the "test cases and expected results" were automatically derived from an abstract model of the system under test (SUT). MBT has been applied in the literature to test the functional and non-functional characteristics of a software product [4].

Unlike conventional software systems, research on the use of the MBT approach to assure the quality of IoT software applications is in an early stage because of the novelty of the IoT approach itself. However, there have been several attempts in this direction in the past decade. To this end, the goal of this study is to identify and evaluate the present status of model-based QA of IoT software applications. The well- known methodology of systematic literature study (SMS) is employed to gather data from papers published in the past decade and analyze them. Following this approach, the attempt is to answer several relevant research questions (RQs) to identify the current achievements, challenges, research gaps, and future directions.

The paper is organized as follows: the background and related works are described in Section II, the research method- ology is presented in Section 3, an analysis of the results is provided in Section 4, threats to the validity of the study are discussed in Section 5, and, finally, the conclusions are reported in Section 6.

\section{Background and Related Work}

During the past decade, significant effort has been spent in researching the field of IoT. One of the most significant areas of research is QA. A systematic mapping is the best means to survey the data gathered by researchers who have studied QA in IoT and identify the main challenges encountered.

An SMS aims to identify and collect relevant literature on a research topic to present the research qualitatively and quantitatively [5]. An SMS also gathers and evaluates the results of a research with the aim of providing a complete and detailed summary of the current literature relevant to the field of focus during a specific period. Based on literature [5], an SMS includes three primary stages. Figure 2 illustrates these stages in detail. The first stage is the planning stage, which produces a protocol for specifying the research questions and how to answer them. The second stage is the search stage, which identifies that strategy that will be adopted to select relevant published studies. The final stage is the review stage, which is used for extracting and synthesizing data.

This SMS focuses on the QA of IoT software applications. More specifically, the study focuses on how models have been used for the QA and testing of IoT software applications. Recently, several literature studies have been published concerning some aspects related to IoT quality. For example, Marwah et al. [6] have evaluated IoT implementation techniques by considering QA characteristics. Further, the study examined various techniques for implementing IoT. It concluded that most IoT techniques lack tools to support automation techniques. Foidl et al. [7] have outlined QA requirements of IoT into six categories environment, user, service level agreement, organization, security, and data management. Further, they attempted to describe the QA of IoT 
applications by subdividing it into four categories derived from the six QA requirement categories.

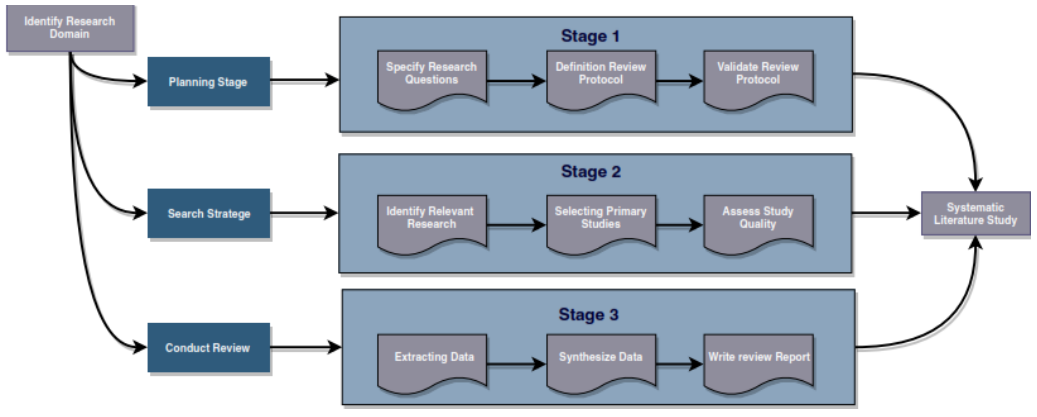

Fig. 2. Systematic Literature Study stages

Gary et al. [8] conducted one of the early studies and produced a systematic mapping of the quality for IoT applications. The study focused on quality of service (QoS) in IoT applications. This mapping study provided a view of the state of QoS approaches in IoT by assuming that QoS can be assured at different layers of the IoT architecture. However, the study focused on quality aspects from the perspective of QoS and high-level quality standards without going into the detailed methodologies of assuring various quality aspects. Later, Banerjee et al. [9] classified the quality data into two categories specification and conformance. The study also attempted to improve the quality of IoT by analyzing two daily life cases requiring a high level of quality. The study concluded that to ensure the quality of IoT application, three quality areas should be examined.

Concerning the quality of IoT applications, several map- ping and literature studies have been published recently. These studies focused on either the big picture of IoT quality or individual quality aspects. For example, Ahmed et al. [10] conducted an extensive SMS on most quality aspects covered by the ISO/IEC 25000 standard that are applicable to IoT applications. Lepekhin et al. [11] also addressed several quality aspects in their systematic mapping study on IoT challenges. Venceslau et al. [12] conducted a systematic mapping study on IoT semantic interoperability, which is a specific aspect of quality. Porras et al. [13] focused on security in his SMS, which is another aspect of IoT application.

Despite the various published studies on IoT quality, a gap exists in addressing specific methodologies to assess particular aspects of quality in IoT applications. A significant gap also exists in the literature on information about how to migrate quality assessment and testing methodologies to the IoT era. As mentioned earlier in this paper, MBT is a successful and well-established approach in conventional software testing. However, there is no SMS on how this approach has been used earlier within IoT software applications to assess some specific quality aspects. This study aims to fill these gaps and systematically study the MBT approaches used directly or indirectly in the literature to assess any quality aspect of IoT software applications. 


\section{$3 \quad$ Research Methodology}

Following the well-known methodology of SMS [14-16], this study follows a threestage method to formulate relevant research questions (RQ), identify a search strategy, and specify the selection criteria. The following subsections illustrate these stages in detail.

\subsection{Research questions}

A set of relevant RQs is proposed and answering each one of them requires an effort to analyze the results based on our study methodology. The RQs were chosen with two main purposes to conduct a mapping of the published papers that proposed model-based QA and to review the content of the chosen papers in detail. Hence, this study entails more than just mapping publications. Considering this aim, the following RQs were chosen.

- Publication-related RQs

RQ1.1: Describe the development in the number of published studies in model-based quality assessment of IoT software applications in the past decade?

RQ1.2: How many articles were published per year?

RQ1.3: Which countries have an active role in publishing the articles?

RQ1.4: Which venues have higher article counts?

RQ1.5: Which authors have the highest number of publications?

RQ1.6: What are the authors' affiliations?

- Content related RQs

RQ2.1: What are the quality assessment and testing levels addressed by the articles? RQ2.2: Which type of test techniques were proposed to generate the test cases?

RQ2.3: What type of test bed was used to execute the QA test cases?

RQ2.4: Which tools were used to generate the test cases for QA purposes?

RQ2.5: What are the features of the testing tools?

RQ2.6: What type of models were used in the QA process?

RQ2.7: Which specific criteria of the ISO/IEC 25000 quality model have been addressed in the literature?

\subsection{Search strategy}

The study seeks to conduct an SMS on the model-based QA of IoT software applications. The search strategy is a systematical structural part of the SMS that utilizes keywords such as "Internet of Things," "model-based testing," and "quality assessment" for searching through the indexing databases. The search strategy also uses key terms from the search questions to obtain accurate results [17]. Here, the search scope should be identified to build an efficient search strategy that can return the highest number of related articles. 
The search scope consists of more than one dimension, such as publication year and publication venue. The domain searched includes research studies that were published from 2009 to 2019 . The search process was performed within four well-known electronic databases. The search items were journals, conferences, and workshop papers.

\subsection{Search Method}

To select primary studies, automatic and manual searches were used. Automatic search was performed by entering search strings into the search engines of electronic libraries. Manual search was performed by scanning and analyzing the articles after applying the inclusion and exclusion criteria. Well-known inclusion and exclusion practices from the literature [18] were used.

\subsection{Identify relevant research}

As mentioned previously, the automatic search process was performed on four electronic databases (see Table1), which are the most relevant libraries in computer science $\&$ engineering. These databases ensured high coverage of published research studies [19].

Table 1. Electronic databases used in automated search

\begin{tabular}{|l|l|}
\hline \multicolumn{1}{|c|}{ Electronic Databases } & \multicolumn{1}{c|}{ Uniform Resource Locator (URL) } \\
\hline IEEEXplore & http://ieeexplore.ieee.org \\
\hline ACM digital library & http://dl.acm.org.com \\
\hline ScienceDirect & http://www.sciencedirect.com \\
\hline SpringerLink & https://www.springer.com \\
\hline
\end{tabular}

The selected libraries also provided support for text combinations via logical operators for automatic search. For automated search, the study used a combination of search strings to address the RQs. Within these search strings, more than one keyword was used. To be specific, the three keywords, "Internet of Things," "model-based testing," and "quality assessment" were used. To improve the accuracy of the queries, the study used the logical operators OR and AND to construct more meaningful strings for the search engine. The search strings used to search through the electronic databases and the respective number of outcomes of the search process are provided in Table 2 . The total number of papers that appeared in the databases in the first stage was 4,570. As some studies could be included in more than one database, manual search was applied to identify duplicate studies and select the primary entries. As a result, 2,668 papers remained. 
Paper-Model-Based Quality Assessment of Internet of Things Software Applications...

Table 2. Search string and number of outcome papers from the electronic databases

\begin{tabular}{|c|c|c|c|}
\hline Electronic Databases & Search String & Total papers & $\begin{array}{c}\text { After Duplicate } \\
\text { limitation }\end{array}$ \\
\hline IEEEXplore & \begin{tabular}{|l|} 
(“internet of things" OR" IoT") AND \\
("model-based testing" OR" MBT") (Internet \\
of things applications" OR" IoT") AND \\
("quality assurance" OR" QA")
\end{tabular} & 2,387 & 1,372 \\
\hline $\mathrm{ACM}$ & \begin{tabular}{|l|} 
("internet of things" OR "IoT") AND \\
("model testing" OR "model software test- \\
ing")("internet of things" OR "IoT applica- \\
tions") AND ("QA" OR "quality assur- \\
ance")("internet of things" OR "IoT") AND ( \\
"Quality" OR "Reliability" OR "Verifica- \\
tion" OR "Validation" OR "Testware" OR \\
"Testing Data" OR "Testbed" OR "Perfor- \\
mance" OR "Security")
\end{tabular} & 963 & 459 \\
\hline ScienceDirect & 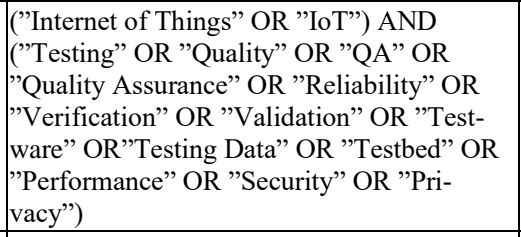 & 435 & 380 \\
\hline SpringerLink & $\begin{array}{l}\text { ("Internet of Things" OR "IoT") AND } \\
\text { ("Test" OR "model testing"OR"model soft- } \\
\text { ware testing" OR "Testing" OR "Quality" } \\
\text { OR "QA" OR "Quality Assurance" OR "Re- } \\
\text { liability" OR "Verification" OR ”Valida- } \\
\text { tion" OR "Testware" OR "Testing Data" OR } \\
\text { "Performance" OR "Security" OR "Pri- } \\
\text { vacy") }\end{array}$ & 785 & 457 \\
\hline \multicolumn{2}{|l|}{ Total } & 4,570 & 2,668 \\
\hline
\end{tabular}

\subsection{Selection criteria}

The papers collected using automatic search strings were included based on the titles, abstracts, and keywords of the papers in all electronic databases. As general search strings were used to ensure that any relevant paper was not ignored, the automatic search produced a large number of papers. Thus, the exclusion criteria aimed to reduce the number of papers based on their relevance. The study applies the inclusion and exclusion criteria on the selected papers.

- The following inclusion criteria were used:

IC1: The papers have a direct relation to IoT software application.

IC2: The papers which have been focusing on assessing and testing any quality aspect (based on ISO/IEC 25000 software quality model) of IoT software application.

IC3: The papers which have been focusing on using model (i.e., model-based) for testing and assessing a specific quality aspect.

IC4: The papers which have presented methodologies for evaluating any quality aspect of IoT software applications. 
- The exclusion criteria that have been used in this study are as follows:

EC1: The papers without full text.

EC2: The papers that have not been written in English.

EC3: The papers which have no "IoT" as the index terms.

EC4: The papers that were not concerning model for quality assessment.

EC5: The papers that did not actually discuss any quality aspect.

EC6: The papers that focus on static analysis without actual testing of the quality aspect.

EC7: The survey papers on IoT quality aspects that have no evaluation results.

EC8: The papers which present ideas without any implementation or results on assessment and testing methods.

The outcome papers after eliminating the duplicated papers are 2,668, as shown in the second column of Table 3. After using the (EC1-EC8), the total number of papers has been reduced to 54, as shown in Figure 3.

Table 3. Number of outcome papers after applying exclusion criteria

\begin{tabular}{|l|c|c|}
\hline \multicolumn{1}{|c|}{ Electronic Databases } & No. after neglecting the duplicate & $\begin{array}{c}\text { No. after applying } \\
\text { EC1-EC8 }\end{array}$ \\
\hline IEEEXplore & 1,372 & 33 \\
\hline ACM & 459 & 10 \\
\hline ScienceDirect & 380 & 8 \\
\hline SpringerLink & 457 & 3 \\
\hline Total & 2,668 & 54 \\
\hline
\end{tabular}

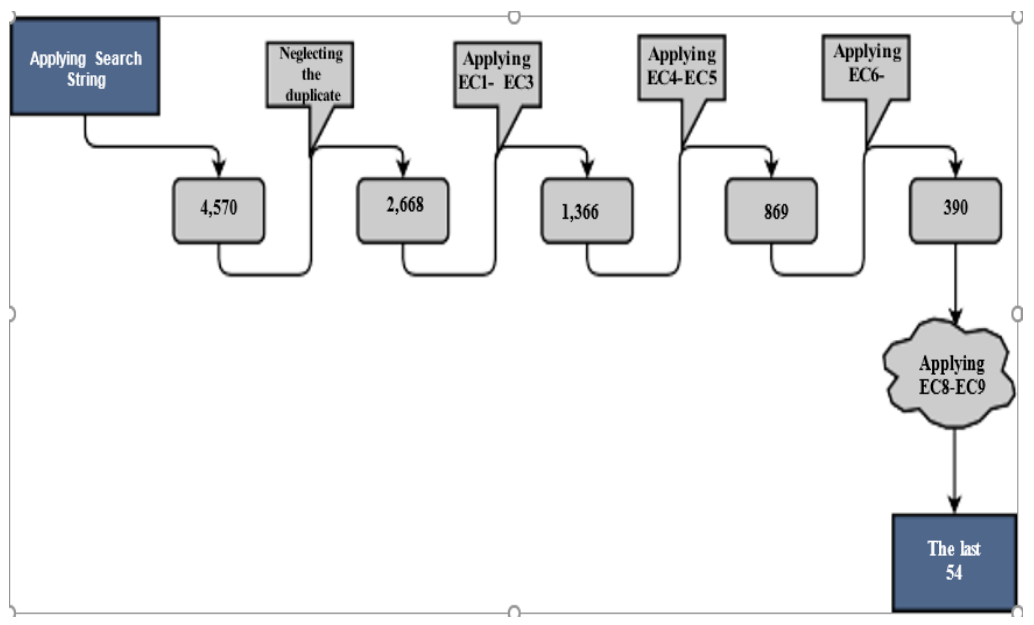

Fig. 3. Stages of exclusion criteria and number of papers for each stage 


\section{Data Availability Statement}

This systematic study is reporting the list of final selected papers and the information assigned to each paper. This list is not attached here for the reason of space constraints. However, it is available online at https://docs.google.com/spreadsheets/SLSIoT

\section{$5 \quad$ Analysis of Results}

The data collected using the steps mentioned are analyzed to address the RQs of this study. The following subsections discuss the answer of each RQ in detail.

\section{1 (RQ1.1 and RQ1.2) Ratio of publication growth}

The papers selected over the past decade (2009-2019) were analyzed to determine the progress of published research. Figure 4 and Figure 5 illustrate the number of published studies and the ratio of publications per year. It is clear from the figures that during the period 2009-2012, there was no published research that treated the modelbased QA of IoT software applications. A few published studies surveyed the aspects of IoT quality from various perspectives. However, no published research focused on the assessment of IoT software, particularly through the model-based perspective.

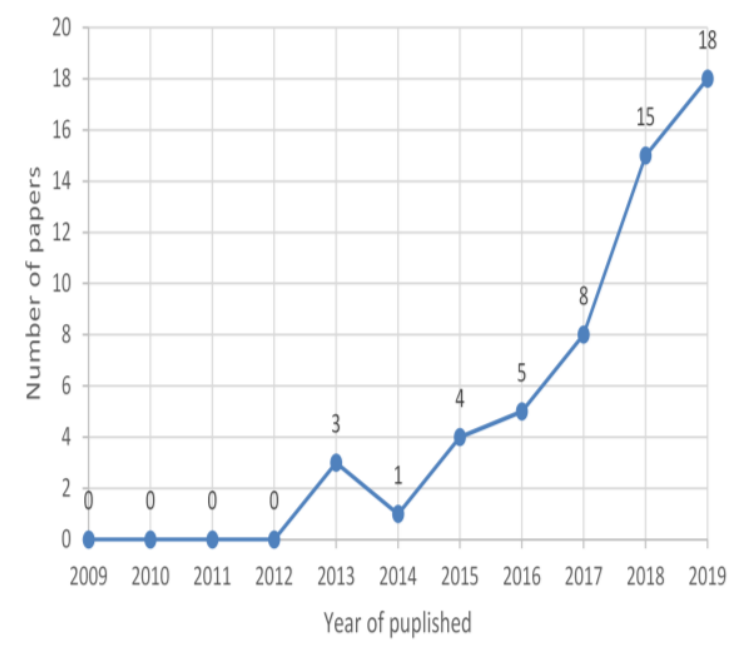

Fig. 4. Distribution of the publication papers per year 


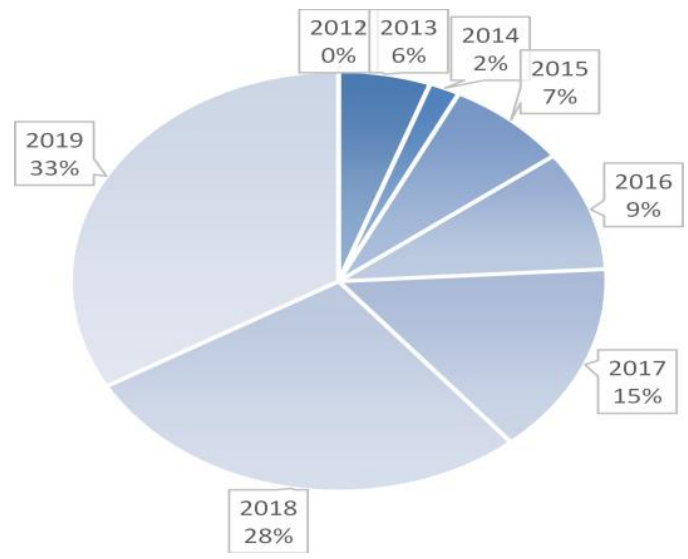

Fig. 5. The ratio of the publication per year

In 2016, researchers started to investigate the QA of IoT software applications. To this end, the ratios of publications in 2016 and 2017 are $9 \%$ and 15\%, respectively. In 2018,15 papers were published, which is almost $28 \%$ of the total number of published papers, whereas, in 2019, a significant number of papers were published in this area (18 papers), which was approximately $33 \%$ of the total ratio. This increase in the publication ratio may be caused by several factors, such as the general increase of interest in IoT because of its wide range of applications and the necessity of QA for those IoT software applications that interface with life critical matters.

\section{2 (RQ1.3 and RQ1.4) Geographical spread and nature of publications}

Compilation of data extracted from authors' affiliations from the selected papers indicates that research activities in this field have been widespread. The contribution of countries was determined based on the authors' affiliations in each paper. Each country is counted once per paper, even if more than one author from the same country contributed to that paper. As it is clear from Figure 6, France and China were the most productive countries for publications in this area, with eight papers published by each of them. The USA and India rank after them with five and four published papers, respectively. Further, Italy, Brazil, Germany, Finland, and the UK also appeared in this ranking with three papers each. Another part of the publication analysis in this study is the publication type, such as conference, journal, and workshop. Figure 7 presents the results of this analysis. It is clear from Figure 8 and Table 4 that more than half of the selected papers (approximately 57\%) were published in conference venues, whereas approximately $31 \%$ were published in journals and only $12 \%$ were published in workshops. The screening of papers published in conferences and other active fora in this research area is presented in Figure 8. As it is clear from the figure, the "IEEE World Forum on Internet of Things (WF-IoT)" published the highest number of papers in this research area. 


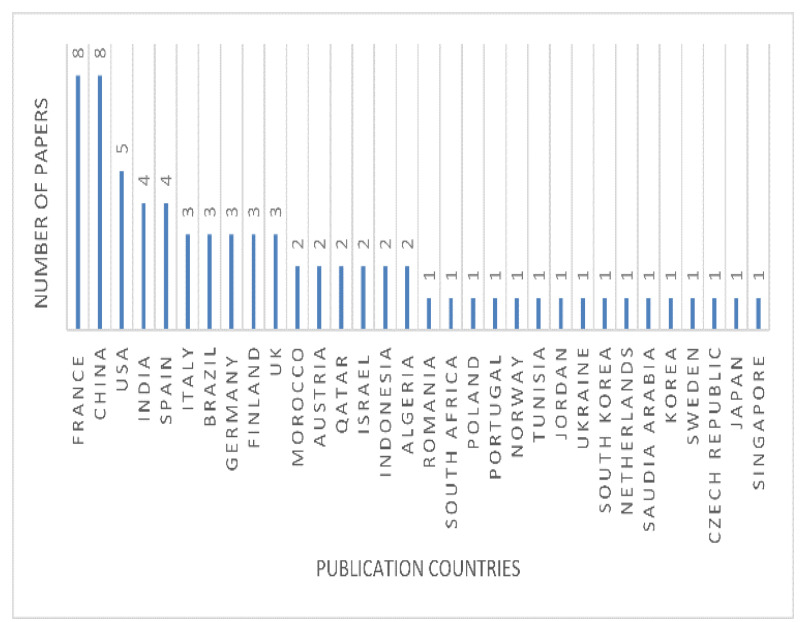

Fig. 6. The publication countries

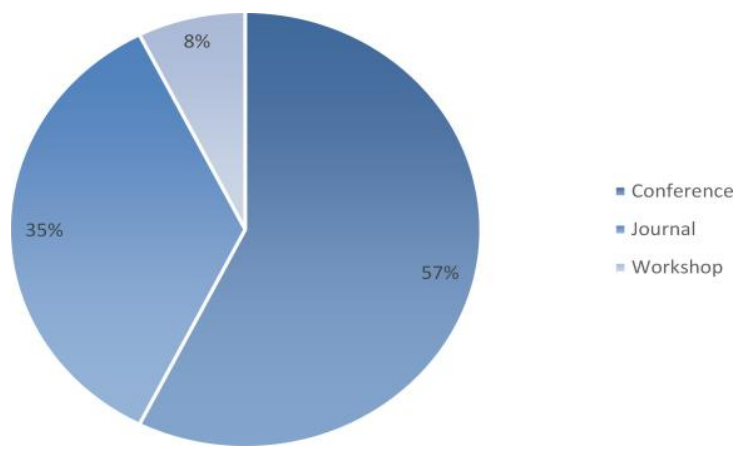

Fig. 7. The ratios of publication type

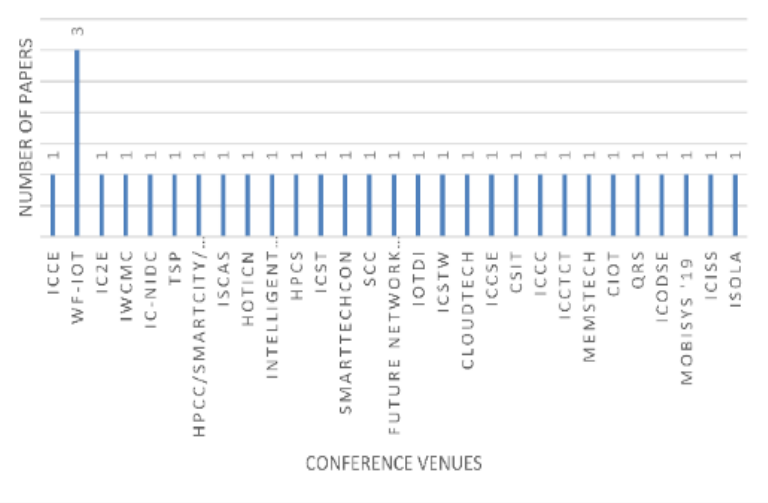

Fig. 8. The conferences venues 
Table 4. List of the active conferences with their abbreviations

\begin{tabular}{|l|l|}
\hline Abbreviation & \\
\hline ICCE & IEEE International Conference on Consumer Electronics \\
\hline WF-IoT & IEEE World Forum on Internet of Thing \\
\hline IC2E & IEEE International Conference on Cloud Engineering \\
\hline IWCMC & International Wireless Communications \& Mobile Computing Conference \\
\hline IC-NIDC & International Conference on Network Infrastructure and Digital Content \\
\hline TSP & International Conference on Telecommunications and Signal Processing \\
\hline WF-IoT & IEEE World Forum on Internet of Things \\
\hline ISCAS & IEEE International Symposium on Circuits and Systems \\
\hline HotICN & IEEE International Conference on Hot Information-Centric Networking \\
\hline HPCS & International Conference on High Performance Computing Simulation \\
\hline ICST & IEEE International Conference on Software Testing, Verification and Validation \\
\hline SmartTechCon & International Conference on Smart Technologies For Smart Nation \\
\hline SCC & IEEE International Conference on Services Computing \\
\hline IoTDI & IEEE/ACM International Conference on Internet-of-Things Design and Implementation \\
\hline ICSTW & $\begin{array}{l}\text { IEEE International Conference on Software Testing, Verification and Validation Work- } \\
\text { shops }\end{array}$ \\
\hline ICCSE & International Conference on Computer Science \& Education \\
\hline CSIT & International Conference on Computer Science and Information Technology \\
\hline ICCC & IEEE International Conference on Computer and Communications \\
\hline ICCTCT & International Conference on Current Trends towards Converging Technologies \\
\hline CIoT & Cloudification of the Internet of Things \\
\hline QRS & IEEE International Conference on Software Quality, Reliability\& Security \\
\hline ICoDSE & International Conference on Data and Software Engineering \\
\hline
\end{tabular}

\section{3 (RQ1.5 and RQ1.6) The active author and his affiliation}

As mentioned previously, this RQ aims to analyze the papers selected in this study to identify active authors and co-authors as well as their affiliations. The authors who have a large number of papers are Abbas Ahmad (three papers) and Bruno Legeard (two papers), and both of them were working in Easy Global Market; Fabrice Bouquet, affiliated to the FEMTO- ST Institute, and Elizabeta Fournere, working with Smart Testing Solutions and Services, with two published papers each, ranked second.

\section{$5.4 \quad$ (RQ2.1) Testing levels}

An essential RQ that was addressed in this study concerned the level of testing that has been applied for a quality aspect using the model-based approach. To address this question, the selected papers were scanned extensively to identify the level of testing used in the relevant published papers. The outcome of this analysis has been presented in Figure 9. It is clear from Figure 9 that most selected papers (approximately 27\%) presented integration testing, approximately $24 \%$ employed system testing and approximately $18 \%$ presented unit testing. Further, approximately $11 \%$ introduced acceptance testing, whereas approximately $15 \%$ did not address any specific level of testing. 


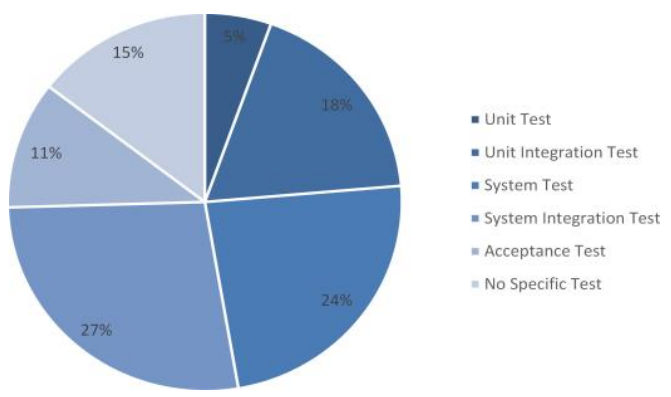

Fig. 9. Testing levels

\section{5 (RQ2.2) Testing technique}

A significant outcome of this study was the mapping of the model-based testing technique used within IoT software applications. An extensive analysis of the selected papers indicates that three approaches were used in the literature in which the test cases were generated. These approaches for test generation were based on a graphical model, mathematical model, and test bed. Among the selected papers, approximately $43 \%$ used a graphical model to generate test cases, approximately $18 \%$ used a mathematical model to generate test cases, and approximately $39 \%$ relied on an implemented model of the test bed to generate test cases. Figure 10 and Table 5 present the results of this analysis.

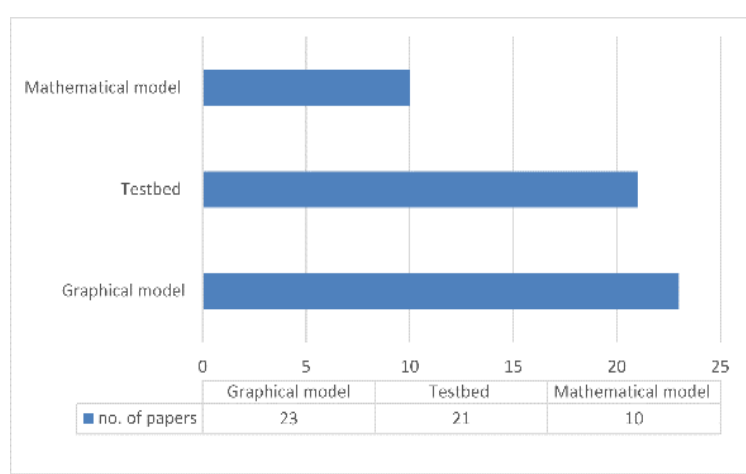

Fig. 10.Models used for test generation 
Paper-Model-Based Quality Assessment of Internet of Things Software Applications...

Table 5. Literature mapping of the models used for test generation

\begin{tabular}{|l|c|c|}
\hline \multicolumn{1}{|c|}{ Test techniques } & Extracted papers & Total number \\
\hline \multirow{4}{*}{ Graphical Model } & {$[20][21][22][23][24][25][26]$} & \\
& {$[27][28][29][30][31][32][33]$} \\
& {$[34][35][36][37][38][39][40]$} \\
{$[41][42]$} & 23 \\
\hline \multirow{2}{*}{ Mathematical Model } & {$[43][44][45][46][47][48][49]$} & \\
\hline \multirow{2}{*}{ Testbed } & {$[50][51][52]$} & \multirow{2}{*}{10} \\
& {$[53][54][55][56][57][58][59]$} & \multirow{2}{*}{21} \\
\hline
\end{tabular}

\section{6 (RQ2.3) Test execution environment}

It is also of interest to know which testing environment was used for model-based QA of IoT software applications. After scanning the selected papers, it is clear that either real devices or emulators were used as the test execution environment. It is also noticeable that a few published papers did not provide enough details of the test execution environment they used. Figure 11 presents a clear mapping of the test execution environments used in the selected published papers. It is clear from the figure that approximately $59 \%$ of the selected papers used emulators to generate and execute the test cases, whereas approximately $41 \%$ executed the test using real devices.

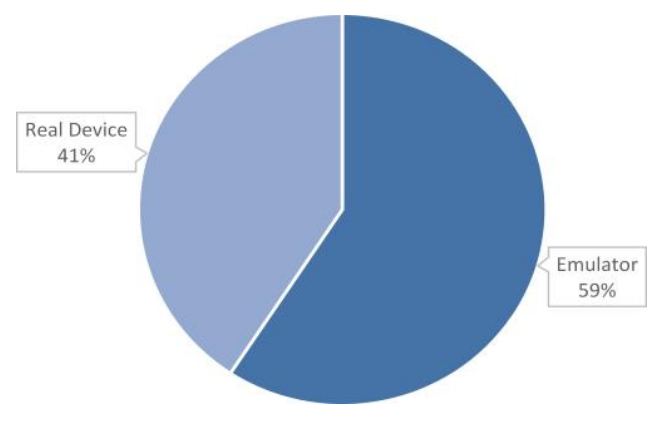

Fig. 11.Mapping of the test execution environment

During the detailed scanning and reading of the selected papers, several issues were identified regarding the test execution environment. These issues were particularly related to the authenticity of the emulator environment for generating and executing the test cases and the differences expected when running the tests on real IoT software applications in real devices. Table 6 summarizes these issues. 
Table 6. Issues found in the literature for testing of the software application within emulator and real IoT devices

\begin{tabular}{|l|l|l|}
\hline \multicolumn{1}{|c|}{ Issue } & \multicolumn{1}{|c|}{ Emulator Testing Environment } & \multicolumn{1}{c|}{ Real Device Testing Environment } \\
\hline Availability & $\begin{array}{l}\text { The emulator is open and free software in most } \\
\text { cases }\end{array}$ & $\begin{array}{l}\text { The use of real devices for testing is } \\
\text { costly and it may raise the budget of the } \\
\text { product and affects the delivery of the } \\
\text { software product }\end{array}$ \\
\hline Test case & $\begin{array}{l}\text { The emulator is suitable for } \\
\text { certain types of functional test case Executions }\end{array}$ & $\begin{array}{l}\text { The real devices deal with strict perfor- } \\
\text { mance testing issues, in which it is diffi- } \\
\text { cult to get an indication by the emulator }\end{array}$ \\
\hline Battery state & $\begin{array}{l}\text { The emulator is not able to simulate the battery } \\
\text { issues }\end{array}$ & $\begin{array}{l}\text { Real devices can inspect the performance } \\
\text { of the battery }\end{array}$ \\
\hline Memory issue & $\begin{array}{l}\text { The memory storage level of the emulator } \\
\text { tends to be far more than the real devices }\end{array}$ & $\begin{array}{l}\text { The memory level of the real devices } \\
\text { tends to be far less than the emulators }\end{array}$ \\
\hline Test application & $\begin{array}{l}\text { In many cases, it is not possible to run all types } \\
\text { of IoT software applications om emulators }\end{array}$ & $\begin{array}{l}\text { The real devices are by themselves sup- } \\
\text { port for the IoT applications }\end{array}$ \\
\hline
\end{tabular}

\section{7 (RQ2.4 and RQ2.5) Model-based testing tools for IoT software applications}

This RQ addresses the model-based test generation tools used for IoT software applications in the literature. It was noticeable during the detailed scanning of the selected studies that several published papers addressed the testing of IoT software applications without using any specific testing tools. It was clear that [22], [23], [35], [36], [40], [43], [45], [46], [48], [50], [53], [55], [69], [70] did not use any specific tools. Instead, the test cases were generated through empirical observation of the system during experimental studies. However, in 25 out of the 54 published papers, a testing generation or execution tool was used. Table 7 summarizes these tools and their features in detail.

Table 7. The features of the proposed test tool

\begin{tabular}{|l|c|l|}
\hline Tool's name & $\begin{array}{c}\text { The pub- } \\
\text { lished } \\
\text { study }\end{array}$ & \multicolumn{1}{|c|}{ Tool's features } \\
\hline PROMELA & {$[37]$} & $\begin{array}{l}\text { A modeling language with processes, protectors, channels, and simple varia- } \\
\text { bles that can check the model for standard and user-defined properties through } \\
\text { a full or a partial investigation of the model's state space }\end{array}$ \\
\hline CloudSim & {$[49]$} & $\begin{array}{l}\text { A framework for modeling and simulation of loud computing infrastructures } \\
\text { and services. }\end{array}$ \\
\hline Apache JMeter & {$[72]$} & $\begin{array}{l}\text { An open-source Java-based tool that designed to load functional test behavior } \\
\text { and measure performance. }\end{array}$ \\
\hline Spec Explorer & {$[20]$} & $\begin{array}{l}\text { A model-based testing tool from Microsoft that can generate the test automati- } \\
\text { cally within visual studio or any other unit testing framework }\end{array}$ \\
\hline Wireshark & {$[60]$} & $\begin{array}{l}\text { An open-source analyzer used to analyses software and communications proto- } \\
\text { col development }\end{array}$ \\
\hline Petri net & {$[44],[64]$} & \begin{tabular}{l} 
A mathematical modeling language for the description of distributed systems. \\
\hline Sentilo
\end{tabular} \\
\hline 56$]$ & $\begin{array}{l}\text { A cross-platform to share information among heterogeneous systems to easily } \\
\text { integrate legacy applications }\end{array}$ \\
\hline
\end{tabular}




\begin{tabular}{|l|c|l|}
\hline CoAP & {$[61][73]$} & $\begin{array}{l}\text { The Constrained Application Protocol (CoAP) an expert web transfer protocol } \\
\text { for use with constrained networks and nodes. Key aspects of CoAP are small } \\
\text { message overhead thus limiting the use of fragmentation, simplicity for con- } \\
\text { strained environments including key web concepts such as URIs and content- } \\
\text { types. This test suite can be used to test CoAP server implementations for se- } \\
\text { curity flaws and robustness problems }\end{array}$ \\
\hline Metamodel & {$[21]$} & $\begin{array}{l}\text { A tool for analysis, construction, development of the frames, rules, constraints, } \\
\text { models, and theories that is used for modeling }\end{array}$ \\
\hline Benchmark & $\begin{array}{c}{[24][51]} \\
{[66]}\end{array}$ & $\begin{array}{l}\text { A commercial testing tool to compare business processes and performance } \\
\text { metrics to the best practices of other companies }\end{array}$ \\
\hline NS & {$[58][65]$} & $\begin{array}{l}\text { A discrete event simulator targeted at networking research to provide substan- } \\
\text { tial support for simulation of TCP, routing, and multi cast protocols over wired } \\
\text { and wireless networks }\end{array}$ \\
\hline TTCN-3 & {$[25]$} & $\begin{array}{l}\text { Testing and Test Control Notation version 3 is a well-known testing language } \\
\text { that used in conformance testing of communicating systems }\end{array}$ \\
\hline F-Interop & {$[62]$} & $\begin{array}{l}\text { A compliance test tool for interoperability of implementation and to explore } \\
\text { various testing schemes and configurations by interconnecting devices under } \\
\text { tests with the server testing tools }\end{array}$ \\
\hline JUnit & {$[26]$} & $\begin{array}{l}\text { A Java-based unit testing framework that been influential in the development } \\
\text { of test-driven development }\end{array}$ \\
\hline
\end{tabular}

\section{8 (RQ2.6 and RQ2.7) Mapping addressed quality aspects}

The quality aspects of software applications have generally been formulated using the ISO/IEC 25000 software quality model [74]. Not all these aspects have been assessed in the literature for IoT software applications. Moreover, the model-based assessment was used to evaluate only a few of those assessed in the literature. An analysis of the selected studies indicated that model-based assessment had been used with eight quality aspects performance, suitability, compatibility, usability, reliability, security, maintainability, and portability. Figure 12 and Table 8 present the publication ratio and mapping of published papers that address the quality aspects. The following subsections provide a short description of how each quality aspect has been addressed.

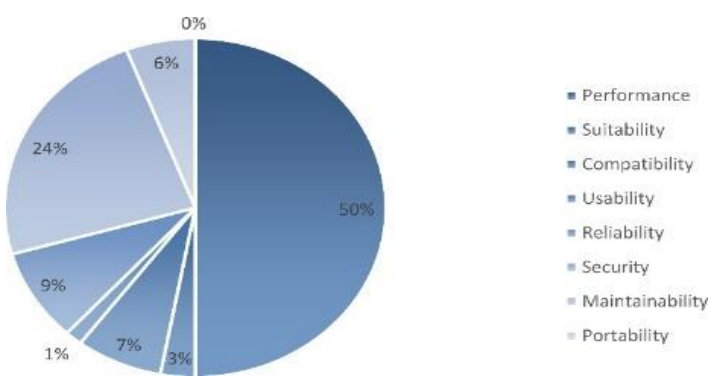

Fig. 12.Publication ratio for each quality aspects 
Paper-Model-Based Quality Assessment of Internet of Things Software Applications...

Table 8. Mapping the published papers with the addressed IoT software quality aspects

\begin{tabular}{|l|c|c|}
\hline \multicolumn{1}{|c|}{ Quality aspect } & Published papers & Total number \\
\hline Performance & {$[20],[23],[24],[30],[33-38],[40],[42],[43],[45-48],[50-56]$,} & 34 \\
\hline Suitability & {$[58],[60],[62],[64-67],[71-73]$} & 2 \\
\hline Compatibility & {$[69],[70]$} & 5 \\
\hline Usability & {$[22],[25],[31],[62],[71]$} & 1 \\
\hline Reliability & {$[64]$} & 6 \\
\hline Security & {$[32],[44],[57],[61],[69],[70]$} & 16 \\
\hline Maintainability & {$[22],[25-29],[38],[39],[41],[43],[48],[57],[59],[63],[65],[68]$} & 4 \\
\hline
\end{tabular}

Performance aspect: Performance in the context of IoT software is the production value of the system under workload [75]. A majority of published papers addressed the performance quality aspect to evaluate IoT software applications. Performance has been addressed from various perspectives in the literature, as described in the following sections.

- The efficiency of whole system functionality that has high performance when the faults are zero. It has been addressed in [38], [43], [50], [51], [72].

- The actual component's implementation, so that the configuration, run-time, management, and monitoring allow achieving high-performance of the system as a whole simultaneously. This has been presented in [35] and [66].

- The ability to run a massive number of devices securely and accurately. And the improvement of data quality and false data detection. Performance has been addressed in this form in [34], [36], [53].

- The ability to detect failures of reactive systems and solve it, as in [20].

- The effect of latency parameter over throughput for the application. For example, when the latency is high, the system spends more time in idle status, which reduces the throughput that will in turn effect on the degree of performance of the system. Performance has been addressed in this form in [30], [33], [37], [56], [60], [67].

- The performance is the stability, response time, transmission rate, and also the accuracy of the system. Performance has been addressed in these forms in [45], [58].

Compatibility aspect: Generally, compatibility is the ability of two systems or more to work together efficiently. From the analysis of the selected papers, there were only five published papers that used modeling for compatibility testing. Compatibility appeared as a significant quality aspect of IoT software application because usually the application is comprised of more than two systems [22].

Usability aspect: Usability is the ease of use of the device or product. For the IoT software applications, usability is addressed as the degree to which a software can be used by users to reach quantified objectives with effectiveness and satisfaction. During the analysis of the selected papers in this study, only one paper found using modeling to assess usability of IoT software applications.

Reliability aspect: Reliability is the extent up to which a specific function of a software system can be executed continuously and efficiently without failing. It is considered a significant feature of IoT software applications because a high degree of reliability is required for critical applications that involve human lives [76]. During this 
study, only six published papers used modeling to assess the quality of an IoT software application.

Security aspect: Within the IoT context, security is the ability of a software to function correctly under malicious attacks [43]. Security plays a strong role in the IoT era. Several research papers have been published focusing on this area. However, during the analysis of the selected papers, it was seen that a few studies used modeling to assess the security of IoT software applications. Only 16 papers have been published in this area.

Maintainability aspect: Maintainability is the ability to restore the operational software state with ease and efficiency after a failure occurs. This is a significant feature for IoT software applications. Generally, it is an essential requirement of stakeholders in the software. During the analysis of the published papers in this study, only four studies were found to use modeling to assess and test the maintainability of IoT software applications.

\section{Threats to Validity}

Like any systematic mapping or literature study, the validity of this study can be questioned. This can be attributed to various aspects such as the searching method used for identifying the published papers, filtering of results, inclusion and exclusion criteria, and possible bias in the data extracted.

One of the probable shortcomings of the research method- ology is the mode of collection of data from the databases. This study searched through only four electronic databases (i.e., IEEE Xplore, ACM digital library, ScienceDirect, and SpringerLink) to identify the selected papers. The main rea- son is that these electronic databases were highly relevant to the study domain. This limitation was overcome by performing several rounds of manual and snowballing search within the lists of references of the selected papers.

The filtering of the papers during the search result may be another drawback because it may relate to the authors' selection and preferences. To overcome this drawback, the authors of the present paper collaborated and performed the filtering independently to obtain different views and achieve non-biased results. Along the same lines, yet another limitation might be the inclusion and exclusion criteria, i.e., the decision regarding which papers were to be included and which were to be excluded. To address this limitation, the research questions were designed clearly and the resultant search strings were formed carefully. The study used well- formed criteria from other similar studies.

\section{Conclusion}

In this study, data from 54 published papers that address model-based testing for IoT applications were extracted. The final set of papers was selected after careful screening processes to select the relevant studies. We based our study on the ISO/IEC 25000 software quality model as a guide for the selected quality characteristics. In addition to a comprehensive mapping study presented in the paper, a detailed literature study has also been presented to analyze the con- temporary critical aspects in this area. Thus, the 
paper forms a base for new opportunities of research in this direction. Several useful analyses of the MBT for IoT can be noted in the paper, for example, the test case generation process, the testing tools used, the models used, and the significant quality characteristics.

\section{References}

[1] Baum, A. "A link to the internet of things, IoT made easy with simple link wi-fi solutions," White Paper, no. SWRY009, pp. 2-12, July 2014.

[2] Rose. S. E. K. and Chapin, L. "The internet of things: an overview," Internet Soc., no. 2, pp. 8-10, October 2015.

[3] ISO/IEC, "Systems and software quality requirements and evaluation (squrre)-guide to square," ISO/IEC 25000, vol. 1, no. 1, pp. 1-11, August 2011.

[4] Utting, M. and Legeard, B. Practical model-based testing: a tools approach, 1st ed. Denise E. M. Penorose, 2006.

[5] Okoli, C. and Schabram, K. "A guide to conducting a systematic literature review of information systems research," Sprouts: Working Papers on Information Systems, vol. 10, no. 6, pp. 10-26, November 2010. https://doi.org/10.2139/ssrn.1954824

[6] Marwah, Q. M. and Sirshar, M. "Software quality assurance in internet of things," International Journal of Computer Applications (0975 - 8887), vol. 109, no. 9, pp. 16-24, January 2015. https://doi.org/10.5120/19217-0964

[7] Foidl, H. and Felderer, M. "Data science challenges to improve quality assurance of internet of things applications," in Dynamic Analysis of Regression Problems in Industrial Systems: Challenges and Solutions, vol. 9953, October 2016, pp. 707-726. https://doi.org/10. 1007/978-3-319-47169-3_54

[8] White, S. C. G. and Nallur, V. "Quality of service approaches in iot: A systematic mapping," Journal of Systems and Software, vol. 132, pp. 186- 203, October 2017.https://doi.org/10.1016/j.jss.2017.05.125

[9] Banerjee, T. and Sheth, A. "Iot quality control for data and application needs," IEEE Intelligent Systems, vol. 32, no. 2, pp. 68-73, Mar 2017.

[10] Ahmed, B. S., Bures, M., Frajtak, K. and Cerny, T. "Aspects of quality in internet of things (IoT) solutions: A systematic mapping study," IEEE Access, vol. 7, pp. 13 758-13 780, 2019. https://doi.org/10.1109/access.2019.2893493

[11] Lepekhin, A., Borremans, A., Ilin, I. and Jantunen, S. "A systematic mapping study on internet of things challenges," in Proceedings of the 1st International Workshop on Software Engineerin Research \& Practices for the Internet of Things, ser. SERP4IoT '19. Piscataway, NJ, USA: IEEE Press, 2019, pp. 9-16. [Online]. https://doi.org/10.1109/serp4iot.2019. $\underline{00009}$

[12] Venceslau, A., Andrade, R. M., Vidal., V. M. P., Nogueira., T. P. and Pequeno, V. M. "IoT semantic interoperability: A systematic mapping study," in Proceedings of the 21 st International Conference on Enterprise Information Systems - Volume 1: ICEIS, INSTICC. SciTePress, 2019, pp. 535-544. https://doi.org/10.5220/0007732605350544

[13] Porras, J., Pänkäläinen, J., Knutas, A. and Khakurel, J. "Security in the internet of things - a systematic mapping study," in Proceedings of the 51st Hawaii International Conference on System Sciences (HICSS), 2018, pp. 3750-3759. https://doi.org/10.24251/hicss.2018.473 
[14] Kitchenham, B., Brereton, O.P., Budgen, D., Turner, M., Bailey, J. and Linkman, S., "Systematic literature reviews in software engineering- a systematic literature review," Information and Software Technology, vol. 51, no. 1, pp. 7-15, Jan. 2009. https://doi.org/10.1016/j.infsof.2008.09.009

[15] Kitchenham, B., Pretorius, R., Budgen, D., Brereton, O.P., Turner, M., Niazi, M. and Linkman, S. "Systematic literature reviews in software engineering - a tertiary study," Inf. Softw. Technol., vol. 52, no. 8, pp. 792-805, Aug. 2010. [Online]. https://doi.org/10. 1016/j.infsof.2010.03.006

[16] Brereton, P., Kitchenham, B.A., Budgen, D., Turner, M. and Khalil, M., "Lessons from applying the systematic literature review process within the software engineering domain," Journal of Systems and Software, vol. 80, no. 4, pp. 571 - 583, 2007, software Performance.https://doi.org/10.1016/j.jss.2006.07.009

[17] Hrabovská, K., Rossi, B. and Pitner, T. "Software testing process models benefits and drawbacks: a systematic literature review," ARXIV, vol. 1, pp. 1-26, January 2019.

[18] Verner, J.M., Brereton, O.P., Kitchenham, B.A., Turner, M. and Niazi, M. "Systematic literature reviews in global software development: A tertiary study," in 16th International Conference on Evaluation Assessment in Software Engineering (EASE 2012), May 2012, pp. 2-11. https://doi.org/10.1049/ic.2012.0001

[19] Dyba, T., Dingsoyr, T. and Hanssen, G.K., "Applying systematic reviews to diverse study types: An experience report," in First International Sympo- sium on Empirical Software Engineering and Measurement (ESEM 2007), Sep. 2007, pp. 225-234. https://doi.org/10.1109/ esem.2007.59

[20] Tappler, M., Aichernig, B.K. and Bloem, R., "Model-based testing iot communication via active automata learning," in 2017 IEEE International Conference on Software Testing, Verification and Validation (ICST), March 2017, pp. 276-287. https://doi.org/10.1109/ icst.2017.32

[21] Karkouch, A., Mousannif, H., Al Moatassime, H. and Noel, T., "A model- driven architecture-based data quality management framework for the internet of things," in 2016 2nd International Conference on Cloud Com- putting Technologies and Applications (CloudTech), May 2016, pp. 252- 259. https://doi.org/10.1109/cloudtech.2016.7847707

[22] Murad, G., Badarneh, A., Quscf, A. and Almasalha, F., "Software testing techniques in iot," in 2018 8th International Conference on Computer Science and Information Technology (CSIT), July 2018, pp. 17-21. https://doi.org/10.1109/csit.2018.8486149

[23] Padmanabhan, M. "Test path identification for internet of things using transaction-based specification," in 2018 International Conference on Current Trends towards Converging Technologies (ICCTCT), March 2018, pp. 1-6. https://doi.org/10.1109/icctct.2018.8551084

[24] Popereshnyak, S., Suprun, O., Suprun, O. and Wieckowski, T., "Iot appli- cation testing features based on the modelling network," in 2018 XIV- th International Conference on Perspective Technologies and Methods in MEMS Design (MEMSTECH), April 2018, pp. 127 131. https://doi.org/10.1109/memstech.2018.8365717

[25] Schieferdecker, I., Kretzschmann, S., Rennoch, A. and Wagner, M., "Iot- testware - an eclipse project," in 2017 IEEE International Conference on Software Quality, Reliability and Security (QRS), July 2017, pp. 1-8. https://doi.org/10.1109/qrs.2017.59

[26] Pontes, P.M., Lima, B. and Faria, J.P., "Izinto: A pattern-based iot testing framework," in Companion Proceedings for the ISSTA/ECOOP 2018 Workshops, ser. ISSTA '18. New York, NY, USA: ACM, 2018, pp. 125- 131. [Online]. https://doi.org/10.1145/ 3236454.3236511

[27] Alves, M.P., Delicato, F.C. and Pires, P.F., "Iota-md: A model-driven approach for applying qos attributes in the development of the iot systems," in Proceedings of the Symposium on 
Applied Computing, ser. SAC '17. New York, NY, USA: ACM, 2017, pp. 1773-1780. [Online]. https://doi.org/10.1145/3019612.3019800

[28] Ahmad, A., Bouquet, F., Fourneret, E. and Legeard, B. "Chapter one - model-based testing for internet of things systems," in Advances in Computers, ser. Advances in Computers, A. M. Memon, Ed. Elsevier, 2018, vol. 108, pp. 1 - 58. [Online]. https://doi.org/10.1016/bs.ad$\underline{\text { com.2017.11.002 }}$

[29] Neisse, R., Steri, G., Fovino, I.N. and Baldini, G. "Seckit: A model-based security toolkit for the internet of things," Computers and Security, vol. 54, pp. 60 - 76, 2015, secure Information Reuse and Integration and Availability, Reliability and Security 2014. [Online]. Available: http://www.sciencedirect.com/science/article/pii/S0167404815000887

[30] Ming, Z.H.O.U. and Yan, M.A., "Qos-aware computational method for iot composite service," The Journal of China Universities of Posts and Telecommunications, vol. 20, pp. 35 - 39, 2013. [Online].http://www.sciencedirect.com/science/article/pii/S1005888513602526

[31] Ahmad, A., Bouquet, F., Fourneret, E., Le Gall, F. and Legeard, B., "Model- based testing as a service for iot platforms," in Leveraging Applications of Formal Methods, Verification and Validation: Discussion, Dissemination, Applications, T. Margaria and B. Steffen, Eds. Cham: Springer International Publishing, 2016, pp. 727-742. https://doi.org/10.1007/978$\underline{\text { 3-319-47169-3_55 }}$

[32] Liu, Y., Zheng, K., Craig, P., Li, Y., Luo, Y. and Huang, X., "Evaluating the reliability of blockchain based internet of things applications," in $20181^{\text {st }}$ IEEE International Conference on Hot Information-Centric Networking (HotICN), Aug 2018, pp. 230-231. https://doi.org/10.1109/hoticn.2018.8606026

[33] Di Pietro, R., Salleras, X., Signorini, M. and Waisbard, E., "A blockchain- based trust system for the internet of things," in Proceedings of the 23Nd ACM on Symposium on Access Control Models and Technologies, ser. SACMAT '18. New York, NY, USA: ACM, 2018, pp. 77-83. [Online]. https://doi.org/10.1145/3205977.3205993

[34] Casado-Vara, R., de la Prieta, F., Prieto, J. and Corchado, J.M. "Blockchain framework for iot data quality via edge computing," in Proceedings of the 1st Workshop on Blockchainenabled Networked Sensor Systems, ser. BlockSys'18. New York, NY, USA: ACM, 2018, pp. 19-24. [Online]. https://doi.org/10.1145/3282278.3282282

[35] Mazzini, S., Favaro, J. and Baracchi, L., "A model-based approach across the iot lifecycle for scalable and distributed smart applications," in 2015 IEEE 18th International Conference on Intelligent Transportation Systems, Sep. 2015, pp. 149-154. https://doi.org/10.1109/ itsc. 2015.33

[36] Jalal, L., Anedda, M., Popescu, V. and Murroni, M. "Qoe assessment for iot-based multi sensorial media broadcasting," IEEE Transactions on Broadcasting, vol. 64, no. 2, pp. 552560, June 2018. https://doi.org/10.1109/tbc.2018.2823914

[37] Kuroiwa, T., Aoyama, Y. and Kushiro, N., "A hybrid testing environment between execution test and model checking for iot system," in 2019 IEEE International Conference on Consumer Electronics (ICCE), Jan 2019, pp. 1-2. https://doi.org/10.1109 $\underline{\text { licce.2019.8661998 }}$

[38] Wang, Z., Dong, X., Li, Y., Fang, L. and Chen, P., "Iot security model and performance evaluation: A blockchain approach," in 2018 International Conference on Network Infrastructure and Digital Content (IC-NIDC), Aug 2018, pp. 260-264. https://doi.org/10.1109 licnidc.2018.8525716

[39] Chu, G. and Lisitsa, A. "Penetration testing for internet of things and its automation," in 2018 IEEE 20th International Conference on High Performance Computing and Communi- 
cations; IEEE 16th International Conference on Smart City; IEEE 4th International Conference on Data Science and Systems (HPCC/SmartCity/DSS), June 2018, pp. 1479-1484. https://doi.org/10.1109/hpcc/smartcity/dss.2018.00244

[40] Kim, D., Lee, E. and Kang, S. "Expediting iot application testing (poster)," in Proceedings of the 17th Annual International Conference on Mobile Systems, Applications, and Services, ser. MobiSys '19. New York, NY, USA: ACM, 2019, pp. 572-573. [Online]. https://doi.org/10.1145/3307334.3328631

[41] Matheu-García, S.N., Hernández-Ramos, J.L., Skarmeta, A.F. and Baldini, G., "Risk-based automated assessment and testing for the cybersecurity certification and labelling of iot devices," Computer Standards \& Interfaces, vol. 62, pp. 64 - 83, 2019. [Online]. https://doi.org/10.1016/j.csi.2018.08.003

[42] Gomes, P., Cavalcante, E., Batista, T., Taconet, C., Conan, D., Chabridon, S., Delicato, F.C. and Pires, P.F. "A semantic-based discovery service for the internet of things," Journal of Internet Services and Applications, vol. 10, no. 1, p. 10, May 2019. [Online]. https://doi.org/10.1186/s13174-019-0109-8

[43] Siegel, J.E., Kumar, S. and Sarma, S.E., "The future internet of things: Secure, efficient, and model-based," IEEE Internet of Things Journal, vol. 5, no. 4, pp. 2386-2398, Aug 2018. https://doi.org/10.1109/jiot.2017.2755620

[44] Li, S. and Huang, J. "Gspn-based reliability-aware performance evaluation of IoT services," in 2017 IEEE International Conference on Services Computing (SCC), June 2017, pp. 483486. https://doi.org/10.1109/scc. 2017.70

[45] Li, L., Rong, M. and Zhang, G., "An internet of things QoE evaluation method based on multiple linear regression analysis," in 2015 10th Inter- national Conference on Computer Science Education (ICCSE), July 2015, pp. 925-928. https://doi.org/10.1109/iccse.2015.7250382

[46] Tambotoh, J.J., Isa, S.M., Gaol, F.L., Soewito, B. and Warnars, H.L.H.S., "Software quality model for internet of things governance," in 2016 International Conference on Data and Software Engineering (ICoDSE), Oct 2016, pp. 1-6. https://doi.org/10.1109/icodse.2016. 7936138

[47] $\overline{\mathrm{ZHOU},}$ M. and MA, Y. "QoS-aware computational method for Iot composite service," The Journal of China Universities of Posts and Telecommunications, vol. 20, pp. 35 - 39, 2013. [Online]. Available: http://www.sciencedirect.com/science/article/pii/S1005888513602526

[48] Li, F., Han, Y. and Jin, C. "Certificateless online/offline signcryption for the internet of things"," Wireless Networks", vol. 23, no. 1, pp. 145-158, Jan 2017". https://doi.org/10. 1007/s11276-015-1145-3

[49] Aazam, M. and Harras, K. A. "Mapping QoE with resource estimation in IoT," in 2019 IEEE 5th World Forum on Internet of Things (WF-IoT), April 2019, pp. 464467.https://doi.org/10.1109/wf-iot.2019.8767254

[50] Gutiérrez-Madroñal, L., La Blunda, L., Wagner, M.F. and Medina-Bulo, I., "Test event generation for a fall-detection iot system," IEEE Internet of Things Journal, vol. 6, no. 4, pp. 6642-6651, Aug 2019. https://doi.org/10.1109/jiot.2019.2909434

[51] Nakhkash, M.R., Gia, T.N., Azimi, I., Anzanpour, A., Rahmani, A.M. and Liljeberg, P., "Analysis of performance and energy consumption of wearable devices and mobile gateways in IoT applications," in Proceedings of the International Conference on Omni-Layer Intelligent Systems, ser. COINS '19. New York, NY, USA: ACM, 2019, pp. 68-73. [Online]. Available: https://doi.org/10.1145/3312614.3312632

[52] Cao, B., Liu, J., Wen, Y., Li, H., Xiao, Q. and Chen, J., "QoS-aware service recommendation based on relational topic model and factorization machines 
for IoT mashup applications," Journal of Parallel and Distributed Computing, vol. 132, pp. 177 - 189, 2019. [Online]. Available: http://www.sciencedirect.com/science/article/pii/S0743731518302375

[53] Batista, B.G., Kuehne, B.T., Frinhani, R.M., Dionisio Filho, M.L. and Peixoto, M.L., "Architecture for internet of things environment management with quality of service assurance," in 2018 International Conference on High Performance Computing Simulation (HPCS), July 2018, pp. 936-942. https://doi.org/10.1109/hpcs.2018.00148

[54] Adjih, C., Baccelli, E., Fleury, E., Harter, G., Mitton, N., Noel, T., Pissard-Gibollet, R., Saint-Marcel, F., Schreiner, G., Vandaele, J. and Watteyne, T., "Fit IoT-lab: A large scale open experimental IoT testbed," in 2015 IEEE 2nd World Forum on Internet of Things (WFIoT), Dec 2015, pp. 459-464. https://doi.org/10.1109/wf-iot.2015.7389098

[55] Kuemper, D., Reetz, E. and Tönjes, R., "Test derivation for semantically described iot services," in 2013 Future Network Mobile Summit, July 2013, pp. 1-10.

[56] Amrutur, B., Rajaraman, V., Acharya, S., Ramesh, R., Joglekar, A., Sharma, A., Lele, A., Mahesh, A. and Sankaran, S. "Poster abstract: An open smart city IoT test bed," in 2017 IEEE/ACM Second International Conference on Internet-of-Things Design and Implementation (IoTDI), April 2017, pp. 323-324. https://doi.org/10.1145/3054977.3057303

[57] Nair, K. K., Dube, E. and Lefophane, S. "Modelling an IoT testbed in context with the security vulnerabilities of south africa," in 2017 3rd IEEE International Conference on Computer and Communications (ICCC), Dec 2017, pp. 244-248. https://doi.org/10.1109/compcomm.2017.8322549

[58] Rahman, H., Ahmed, N. and Hussain, M. I. "A hybrid data aggregation scheme for provisioning quality of service (qos) in internet of things (IoT)," in 2016 Cloudification of the Internet of Things (CIoT), Nov 2016, pp. 1- 5. https://doi.org/10.1109/ciot.2016.7872917

[59] Berhanu, Y., Abie, H. and Hamdi, M. "A testbed for adaptive security for IoT in ehealth," in Proceedings of the International Workshop on Adaptive Security, ser. ASPI '13. New York, NY, USA: ACM, 2013, pp. 5:1-5:8. [Online]. Available: https://doi.org/10.1145/2523501.2523506

[60] Sreeraj, S., Kumar, N. S. and Kumar, G. S. "A framework for predicting the performance of IoT protocols, a use case-based approach," in 2017 International Conference on Smart Technologies for Smart Nation (SmartTechCon), Aug 2017, pp. 577-580. https://doi.org/10. 1109/smarttechcon.2017.8358437

[61] Kanstrén, T., Mäkelä, J. and Karhula, P. “Architectures and experiences in testing iot communications," in 2018 IEEE International Conference on Software Testing, Verification and Validation Workshops (ICSTW), April 2018, pp. 98-103. https://doi.org/10.1109/icstw.2018.00034

[62] Kim, H., Ahmad, A., Hwang, J., Baqa, H., Le Gall, F., Ortega, M.A.R. and Song, J., "Iottaas: Towards a prospective IoT testing framework," IEEE Access, vol. 6, pp. 15 480-15 493, 2018. https://doi.org/10.1109/access.2018.2802489

[63] Marie, P., Lim, L., Manzoor, A., Chabridon, S., Conan, D. and Desprats, T., "Qoc-aware context data distribution in the internet of things," in Proceedings of the 1st ACM Workshop on Middleware for Context-Aware Applications in the IoT, ser. M4IOT '14. New York, NY, USA: ACM, 2014, pp. 13-18. [Online].https://doi.org/10.1145/2676743.2676746

[64] Alodib, M. "Qos-aware approach to monitor violations of slas in the iot," Journal of Innovation in Digital Ecosystems, vol. 3, no. 2, pp. 197 - 207, 2016. [Online]. https://doi.org/10.1016/j.jides.2016.10.010 
[65] Zemmoudj, S., Bermad, N. and Omar, M. "Capm: Context-aware privacy model for iotbased smart hospitals," in 2019 15th International Wireless Communications Mobile Computing Conference (IWCMC), June 2019, pp. 1139-1144. https://doi.org/10.1109/ iwcmc.2019.8766630

[66] Venticinque, S. "Benchmarking physical and virtual iot platforms," in 2019 IEEE International Conference on Cloud Engineering (IC2E), June 2019, pp. 247252.https://doi.org/10.1109/ic2e.2019.00040

[67] Mozny, R., Masek, P., Stusek, M., Zeman, K., Ometov, A. and Hosek, J., "On the performance of narrow-band internet of things (NB-IoT) for delay- tolerant services," in 2019 42nd International Conference on Telecommunications and Signal Processing (TSP), July 2019, pp. 637-642. https://doi.org/10.1109/tsp.2019.8768871

[68] Siboni, S., Sachidananda, V., Meidan, Y., Bohadana, M., Mathov, Y., Bhairav, S., Shabtai, A. and Elovici, Y., "Security testbed for internet-of- things devices," IEEE Transactions on Reliability, vol. 68, no. 1, pp. 23- 44, March 2019. https://doi.org/10.1109/tr.2018. $\underline{2864536}$

[69] Johnston, S.J., Basford, P.J., Bulot, F.M., Easton, N.H., Foster, G.L., Loxham, M., Apetroiae-Cristea, M., Morris, A.K. and Cox, S.J., "Testing smart city environmental monitoring technology using small scale temporary cities," in 2019 IEEE 5th World Forum on Internet of Things (WF-IoT), April 2019, pp. 578-583. https://doi.org/10.1109/wfiot.2019.8767274

[70] Hovhannisyan, D., Eltawil, A. and Kurdahi, F. "Testing topology adaptive irrigation iot with circuits," in 2019 IEEE International Symposium on Circuits and Systems (ISCAS), May 2019, pp. 1-5. https://doi.org/10.1109/iscas.2019.8702559

[71] Yi, L., Ma, J. and Zhang, T. "Hatbed: A distributed hardware assisted testbed for non-invasive profiling of iot devices," in Proceedings of the $2 \mathrm{Nd}$ Workshop on Benchmarking Cyber-Physical Systems and Internet of Things, ser. CPS-IoTBench '19. New York, NY, USA: ACM, 2019, pp. 13-17. [Online]. https://doi.org/10.1145/3312480

[72] Araujo, V., Mitra, K., Saguna, S., and Åhlund, C. "Performance evaluation of fiware: A cloud-based iot platform for smart cities," Journal of Parallel and Distributed Computing, vol. 132, pp. 250 - 261, 2019. [Online]. https://doi.org/10.1016/j.jpdc.2018.12.010

[73] Keophilavong, T. and Rizal, M. N. "Quality of service of protocols performance evaluation for internet of thing applications development using low-cost devices," in Proceedings of the 2019 2Nd International Conference on Information Science and Systems, ser. ICISS 2019. New York, NY, USA: ACM, 2019, pp. 166-170. [Online]. Available: https://doi.org/10.1145/3322645.3322694

[74] Wohlin, C., Runeson, P., Höst, M., Ohlsson, M.C., Regnell, B. and Wesslén, A., "Experimentation in software engineering," in Experimentation in Software Engineering, 2012, pp. 7-24. https://doi.org/10.1007/978-3-642-29044-2_2

[75] Vokolos, F. and Weyuker, E. "Performance testing of software systems," in testing of software systems, 01 1998, pp. 80-87.

[76] Maalel, N., Natalizio, E., Bouabdallah, A., Roux, P. and Kellil, M. "Reliability for emergency applications in internet of things," in Distributed Computing in Sensor Systems (DCOSS), 2013 IEEE International, 05 2013, pp. 361-366. https://doi.org/10. $\underline{1109 / \text { dcoss. } 2013.40}$ 


\section{Authors}

Teeba Ismail Kh. received the B.S. degree in optical electronics engineering from Al-Nahrain University, Baghdad, Iraq, in 2004, and the M.S. degree in Laser and optoelectronics engineering from Al-Nahrain University, Baghdad, Iraq, in 2007. She is currently pursuing the Ph.D. degree in electrical engineering at Salahaldine University, Erbil, Iraq. She is an Assistant Lecturer with the Lebanese French University Faculty of Engineering Erbil, Iraq. Her research interest includes model-based testing area and quality assurance for the IoT software systems. Email: teeba_ismail@lfu.edu.krd, teeba.ismail@su.edu.krd

Ibrahim i. Hamarash Is a Professor of Control Systems Engineering at Salahaddin University since 1993. He received his BSc degree in Electronics and Communication Engineering from Salahaddin University (1988), his MSc. in Control Systems Engineering from Mosul University (1993), his PhD. in Control Systems Engineering from The University of Technology (1999), his ICT project management certificate from UCSD, USA (2005). His research interest includes Robotics and Manipulators, Information Systems and Data Analysis, Modeling, Simulation and Control of Dynamic Systems. Email: - ibrahim.hamad@ukh.edu.krd

Article submitted 2020-01-26. Resubmitted 2020-03-31. Final acceptance 2020-04-01. Final version published as submitted by the authors. 